Tučrul. Ansay/Don Wallace jr. (Hrsg.)

\title{
Introduction to Turkish Law
}

2. Aufl., Ankara: Society of Comparative Law

Dobbs Ferry, N.Y.: Oceana Publications, 1978, XII, 255 S.

Die vorliegende Einführung in das türkische Verfassungs-, Verwaltungs-, Zivil-, Straf- und Verfahrensrecht, ursprünglich als Lehrbuch für den Rechtsunterricht an der verwaltungswissenschaftlichen Fakultät der Middle Eastern Technical University in Ankara gedacht, soll entsprechend dem Wunsch seiner Herausgeber auch ausländische Juristen mit den Grundzügen des türkischen Rechts vertraut machen.

Wie in der ersten Auflage (Ankara 1966), enthält die von Tuğrul Ansay (Universität Ankara) und Don Wallace jr. (Georgetown University, Washington D.C.) herausgegebene Einführung elf Kapitel: I. Güriz, Adnan (Universität Ankara und Hacettepe Universität Ankara): Sources of Turkish Law; II. Ozbudun, Ergun (Universität Ankara): Constitutional Law; III. Aybay, Rona (Middle Eastern Technical University Ankara und Hacettepe Universität Ankara): Administrative Law; IV. Ansay, Tuğrul(Universität Ankara): Law of Persons; V. Ansay, T.: Legal Persons, Societies and Associations; VI. Ansay, T.: Family Law; VII. Ansay, T.: Law of Succession; VIII. Ansay, T.: Law of Property; IX. Ansay, T.: Law of Obligations; X. Gölcüklü, Feyyaz (Universität Ankara): Criminal Law; XI. Ansay, T., und Gölcüklü, F.: Law of Procedure (Civil and Criminal).

Gegenüber der ersten Auflage so gut wie unverändert geblieben ist Kapitel I über die Rechtsquellen. Lediglich ein Abschnitt über Verordnungen mit Gesetzeskraft (Kanun Hükmünde Kararnameler) wurde neu aufgenommen, ein in der ersten Auflage enthaltener Abschnitt über Verordnungen (Kararnameler) wurde gestrichen.

Vollkommen neu geschrieben wurden die Kapitel II über das türkische Verfassungsrecht (1. Aufl.: Ilhan Arsel, Univ. Ankara) und III über das türkische Verwaltungsrecht (1. Aufl.: Tahsin Bekir Balta, Univ. Ankara). Auf eine geschichtliche Einführung folgen im zweiten Kapitel Abschnitte über die Besonderheiten der türkischen Verfassung von 1961, die Legislative, die Exekutive und die Gerichtsbarkeit. Im dritten Kapitel folgen auf eine Einführung eine Darstellung einiger Grundprinzipien des türkischen Verwaltungsrechts sowie Abschnitte über den Verwaltungsaufbau, die Notstands-Sondervollmachten der Verwaltung und die Kontrolle der Verwaltung.

Die Kapitel über das Personen-, das Gesellschafts-, das Erb-, das Sachen- und das Schuldrecht wurden lediglich auf den neuesten Stand gebracht, wobei das Personenstandsgesetz Nr. 1587 vom 5. 5. 1972, das Vereinsgesetz Nr. 1630 vom 22. 12. 1972, das Gesetz Nr. 1163 vom 24. 4. 1969 über die Kooperation und das Gesetz Nr. 903 vom 13. 7. 1967 zur Änderung des Stiftungsrechts als wichtigste Gesetzes-Änderungen und -Neuerungen zu nennen sind.

Kapitel VI über das Familienrecht wurde ebenfalls vollkommen neu geschrieben. Auf eine allgemeine Einführung folgen Abschnitte über Verlöbnis, Ehe, Ehegüterrecht, Scheidung, das Eltern-Kind-Verhältnis, die Vormundschaft, die Pflegeschaft und den gesetzlichen Vertreter. Im Abschnitt über das Eltern-Kind-Verhältnis geht der Verfasser T. Ansay auf die, mehr als 50 Jahre nach der Rezeption des schweizerischen ZGB, noch immer bestehende Problematik der religiösen Imam-Ehen ein und verweist auf das Gesetz Nr. 1826 (Gesetz über die straflose Registrierung nicht registrierter Verbindungen und daraus geborener Kinder) vom 20. 6. 19741.

$1 \mathrm{Zu}$ diesem 5, sogen. Amnestiegesetz s. K. Dilger, Ziviltrauung und religiöse Eheschließung in der Türkei. Zum Problem der Rezeption fremden Rechts, StAZ 1976, S. 353 bis 356 (Text des Gesetzes: S. 372). 
Die Kapitel über Straf- und über Prozeßrecht wurden teilweise erweitert (Straf- und Strafprozeßrecht) oder geändert (Zivilprozeßrecht). Wichtigste Gesetzes-Änderungen und -Neuregelungen sind im Strafrecht das Gesetz Nr. 1490 vom 3. 10. 1971 zur Änderung des TStGB, im Prozeßrecht das Rechtsanwalts-Gesetz Nr. 1136 vom 19. 3. 1969, das Notariats-Gesetz Nr. 1512 vom 18. 1. 1972 und das Gesetz Nr. 1730 über den Kassationshof vom 16. 5.1973.

Im Anhang findet sich eine gegenüber der Erstauflage leider nur unwesentlich erweiterte Auswahlbibliographie englischsprachiger Aufsatz- und Buchtitel zum türkischen Recht, ein türkisch-englisches Glossar der wichtigsten im Text erscheinenden juristischen Termini und ein Sachregister.

Insgesamt wird das Buch dem eingangs erwähnten Wunsch seiner Herausgeber, mit den Grundzügen des türkischen Rechts vertraut zu machen, gerecht. Über den Rahmen dieser Einführung hinausgehende Detailfragen wird man allerdings auch mit Hilfe der o. g. Auswahlbibliographie kaum lösen können.

Otmar Oehring

GENG Wu

\section{Die Staatslehre des Han Fei}

Ein Beitrag zur chinesischen Idee der Staatsräson, Forschungen aus Staat und Recht, Band 44 Springer-Verlag, Wien, New York 1978, VII, 108 S. 48,- DM

Han Fei, gest. 233 v. u. Z., ist der Hauptvertreter der ,,Legalisten“, einer Philosophenschule, deren Ideen zur Herausbildung des chinesischen Kaiserreiches mit seiner zentralisierten Bürokratie bedeutend beigetragen haben. Offizielle Staatsdoktrin war zwar seit dem Jahrhundert vor der Zeitwende der Konfuzianismus, der die Herrschaft von Kaiser und Beamten als moralisch vorbildliches Walten einer Elite legitimiert sah, die sich durch allseitige persönliche Vervollkommnung auszeichnen sollte. In der Praxis jedoch war kein Staatswesen durch bloßen Anstand und den Appell an verantwortungsbewußtes Verhalten zu kontrollieren. Die legalistische Schule forderte demgegenüber, prononciert antikonfuzianisch, die Handhabung von Strafgesetz und Herrschaftstechniken - z. B. den Einsatz von Beamten - und das Ausspielen der eigenen Machtstellung als Instrumente in Händen des Herrschers im Hinblick auf Stabilität und Erweiterung autokratischer Herrschaft. Tatsächlich gelang unter legalistischem Einfluß die Errichtung des ersten chinesischen Großreichs (Ch'in-Dynastie, 221-207), deren Institutionen auch im sich fortan konfuzianisch legitimierenden Kaiserreich über zwei Jahrtausende hinweg beibehalten und fortentwickelt wurden, während die legalistische Ideologie, die die kaiserliche Despotie unverblümt beim Namen nannte, geschmäht wurde. Durch die in der Volksrepublick China in den Jahren 1973-1975 inszenierte AntiKonfuzius-Kampagne wurde jüngst auch eine außerchinesische Offentlichkeit auf diesen Gegensatz z wischen Konfuzianismus und Legalismus aufmerksam. Informationen über den Legalismus sind für den interessierten Nicht-Sinologen jedoch nicht leicht zu erhalten. Zwar ist eine vollständige englische Übersetzung der Schriften Han Feis schon vor Jahrzehnten erstellt worden (Liao, W. K.: The Complete Works of Han Fei Tzu. 2 Vols., London 1939 und 1959), doch blieben die meisten deutschsprachigen Darstellungen zu Han Fei bzw. allgemein zum Legalismus in sinologischer Fachliteratur verborgen. Größere Verbreitung dürfte wohl nur Arthur Waleys , ,Lebensweisheit im Alten China“" erhalten haben, das 1974 als Taschenbuch neu aufgelegt wurde. Waleys Darstellung - die Legalisten heißen bei ihm ,,Realisten“ - ist jedoch nicht mehr ganz auf der Höhe der Zeit. So ist es a prima vista nur zu begrüßen, wenn ein nicht auf Sinologika spezialisierter wissenschaftlicher Verlag es unternimmt, 